J Am Soc Mass Spectrom. 2020 March 04; 31(3): 675-684. doi:10.1021/jasms.9b00113.

\title{
Using Sesame Seed Oil to Preserve and Preconcentrate Cannabinoids for Paper Spray Mass Spectrometry
}

\author{
Bills Brandon, Manicke Nicholas ${ }^{*}$ \\ Department of Chemistry and Chemical Biology, Indiana University-Purdue University \\ Indianapolis. Indianapolis, IN, USA
}

\section{Abstract}

Cannabinoids present a unique set of analytical challenges. An increasing number of states have voted to decriminalize recreational marijuana use, creating a need for new kinds of rapid testing. At the same time, synthetic compounds with activity similar to THC, termed synthetic cannabinoids, have become more prevalent and pose significant health risks. A rapid method capable of detecting both natural and synthetic cannabinoids would be useful in cases of driving under the influence of drugs, where it might not be obvious whether the suspect consumed marijuana, a synthetic cannabinoid, or both. Paper spray mass spectrometry is an ambient ionization technique which allows for the direct ionization of analyte from a biofluid spot on a piece of paper. Natural cannabinoids like THC, however, are labile and rapidly disappear from dried sample spots, making it difficult to detect them at clinically relevant levels. Presented here is a method to concentrate and preserve THC and synthetic cannabinoids in urine and oral fluid on paper for analysis by paper spray mass spectrometry. Sesame seed oil was investigated both as a means of preserving THC and as part of a technique, termed paper strip extraction, wherein urine or oral fluid is flowed through an oil spot on a strip of paper to preconcentrate cannabinoids. This technique preserved THC in dried biofluid samples for at least 27 days at room temperature; paper spray MS/MS analysis of these preserved dried spots was capable of detecting THC and synthetic cannabinoids at low $\mathrm{ng} / \mathrm{mL}$ concentrations, making it suitable as a rapid screening technique. The technique was adapted to be used with a commercially available autosampler.

\section{Keywords}

ambient ionization; direct analysis; saliva; opioids; designer drugs; novel psychoactive substances

\section{Introduction}

Cannabinoids, both natural and synthetic, have become increasingly important analytical targets. Marijuana and cannabidiol oil for recreational use in the United States has been decriminalized in an increasing number of states ${ }^{1-2}$. Concurrently the use of synthetic cannabinoids has increased. Synthetic cannabinoids are synthetically manufactured

*nmanicke@iupui.edu.

Supplementary information

3D printing details and experiments on the preservation capabilities of sesame seed oil substitutes are in supplementary information. 
compounds that mimic the active ingredient of marijuana tetrahydrocannabinol (THC) in structure or function ${ }^{3-4}$. Both types of cannabinoids raise a host of legal and health issues with their increased use. Cannabis has been shown to impact psychomotor skills associated with driving, and the effects are amplified when combined with alcohol. States must find effective methods to detect THC and its metabolites in suspected Driving Under the Influence of Drugs (DUID) incidents ${ }^{5-6}$. In addition, rapid and sensitive testing is needed for a variety of other applications such as employment testing. As of 2015, drug abuse violations made up the highest number of arrests in the United States with marijuana possession making up the largest percent of these $\operatorname{arrests}^{7}$. Synthetic cannabinoids represent a different set of challenges. These compounds are applied to dried plant material marketed as incense "not for human consumption ${ }^{8}$." The dosage and potency are poorly understood, as the compounds come from a library generated during research into cannabinoid receptor agonists for pharmaceutical purposes ${ }^{8-9}$. As a result, the risk of unpredictable side effects and overdose are higher, and users are unlikely to know the exact compound they consumed.

Historically, drug testing for marijuana use has been done in urine, targeting THC metabolites such as 11-Nor-9-carboxy- $\Delta^{9}$-tetrahydrocannabinol (THC-COOH). Detection typically starts with an immunoassay for screening followed by gas chromatography-mass spectrometry (GC-MS) for confirmation ${ }^{10-11}$. Liquid chromatography (LC)-MS has also been investigated due to its ability to detect both THC and synthetic cannabinoids ${ }^{12}$. In addition to urine, alternate biological matrices for detection have included blood, plasma, hair, and oral fluid ${ }^{1,13-14}$. Synthetic cannabinoids pose a problem for these traditional methods. Due to the large number of potential compounds and the wide variation in potency, immunoassays are not sensitive or selective enough ${ }^{15}$. While chromatography methods combined with mass spectrometry are sensitive and selective, they often require extensive sample preparation, special training, and lengthy analysis times. A faster and easier technique would be beneficial as cannabinoid use increases.

Ambient ionization techniques, such as desorption electrospray ionization (DESI), ${ }^{16}$ direct analysis in real time (DART) ${ }^{17}$ and paper spray mass spectrometry, directly analyze samples with minimal preparation. These methods have been investigated for their potential use in drug screening ${ }^{18-22}$. Paper spray, in which biofluid samples are extracted and ionized directly from paper, is a potential option due to its low cost and short analysis time ${ }^{23-25}$. Paper spray has been shown to be capable of detecting certain analytes at sub-ng/mL concentrations ${ }^{26-39}$. However, cannabinoids pose problems for several reasons. Selectivity is a potential issue due to there being over 60 known cannabinoids in cannabis ${ }^{40}$. In addition, both natural and synthetic cannabinoid concentrations in biofluids can be low, and detection limits for paper spray are affected by matrix effects $5,13,25,41$. This problem is compounded for THC and similar compounds, which are labile and degrade rapidly in dried spots through a number of pathways including photo and thermal degradation ${ }^{42}$. Attempts to improve detection limits of paper spray have included adding a solid phase extraction component to a paper spray cartridge ${ }^{31}$, performing a solvent extraction from the biofluid on top of hydrophobic paper ${ }^{26}$ and utilizing a membrane to filter out red blood cells from whole blood $^{28}$. These methods can help lower detection limits, but can also increase the cost or complexity of the analysis. Ideally, the detection limits of paper spray for cannabinoids 
could be improved by concentrating and preserving the analytes without drastically increasing the cost or complexity of the analysis.

Herein we present a simple method to preserve and preconcentrate natural and synthetic cannabinoids for paper spray MS. Sesame seed oil, the vehicle used for the synthetic THC dronabinol $^{43}$, was evaluated for its ability to prevent the volatilization and degradation of cannabinoids in dried urine and oral fluid spots. It is important to preserve cannabinoids in their original form as there are numerous degradation pathways for natural cannabinoids with multiple possible final products which would make quantification difficult ${ }^{42}$. Sesame seed oil was also explored as a means of preconcentrating analytes from urine and oral fluid samples. Preconcentration was assessed by wicking aqueous sample through paper strips with or without sesame seed oil at the front end. A variety of analytes with varying physical properties were analyzed, including both natural and synthetic cannabinoids as well as other pharmaceuticals. Long term preservation was evaluated by determining the detection limits of analytes after 27 days of storage at room temperature in the dark. This approach, termed paper strip extraction, was compared to normal paper spray to determine if preconcentration using sesame seed oil improved detection limits. Finally, paper strip extraction was incorporated into a disposable cartridge and analyzed on a commercial autosampler to show the potential of the technique for rapid analysis.

\section{Materials}

Analytes and their stable isotopic labels (SIL), except atenolol D7 and the synthetic cannabinoids, were obtained from Cerilliant (Round Rock, TX, U.S.A.). Atenolol D7 was obtained from CDN isotopes (Pointe-Claire, QC, Canada) as a powder ( $₫ 98 \%$ purity). ABCHMINACA, AB-CHMINACA metabolite 4, 5-fluoro ADB, 5-fluoro ADB metabolite 2 and AM-2201 and the SIL's of AB-CHMINACA and AM-2201 were obtained under license from the Drug Enforcement Agency (DEA) from Cayman Chemical (Ann Arbor, MI, U.S.A). HPLC grade methanol, acetonitrile, palmitic acid, linoleic acid and oleic acid came from Fisher Scientific (Waltham, MA, U.S.A.). Concentrated sulfuric acid came from EMD Millipore (Burlington, MA, U.S.A.). Whatman grade 31 ET and 3MM chromatography paper came from GE Healthcare Life Sciences (Pittsburgh, PA, U.S.A.). Sesame seed oil, sesamolin, mineral oil and butylated hydroxytoluene came from Sigma-Aldrich (St. Louis, MO, U.S.A.). Sesamin came from ApexBio (Taiwan). The top half of the autosampler cartridge was modeled in Sketchup (Trimble, Sunnyvale, CA, U.S.A.) and 3D printed using a polypropylene filament using an Ultimaker 2+ extended (Geldermalsen, Gelderland, Netherlands). The bottom half of the autosampler cartridge was produced by Prosolia (Indianapolis, IN, U.S.A.). Urine and saliva were provided by a single volunteer.

\section{Methods}

\section{Sesame Oil Preservation}

The ability of sesame oil to preserve different cannabinoids overnight was evaluated relative to oleic acid, a major component of sesame seed oil ${ }^{44}$, and mineral oil. Fentanyl was included as a non-cannabinoid analyte comparison. Urine was spiked at $1 \mu \mathrm{g} / \mathrm{mL}$ for (-)trans- $\Delta^{9}$-tetrahydrocannabinol (THC), 11-Hydroxy- $\Delta^{9}$-tetrahydrocannabinol (11-OH-THC), 
11-Nor-9-carboxy- $\Delta^{9}$-tetrahydrocannabinol (THC-COOH), 11-Nor-9-carboxy- $\Delta^{9}$-THC glucuronide (THC glucuronide), AB-CHMINACA, AM-2201 and fentanyl in a glass vial. The structures for the cannabinoids are shown in Figure 1. Samples were spotted in $5 \mu \mathrm{L}$ aliquots using a glass capillary onto $5 \mathrm{~mm} \times 5 \mathrm{~mm}$ squares of 31ET chromatography paper, with and without $5 \mu \mathrm{L}$ of the different oils, and allowed to dry for 1 hour or 1 day at room temperature on the counter. Internal standards were spotted and allowed to dry immediately prior to analysis to minimize degradation of the labeled compounds. Sample squares were spotted with $2.5 \mu \mathrm{L}$ of methanol containing $500 \mathrm{ng} / \mathrm{mL}$ of the stable isotopic labels (SILs) THC D3, THC-COOH D3, AB-CHMINACA D4, AM-2201 D5 and fentanyl D5 in methanol. THC glucuronide and 11-OH-THC used THC D3 for an internal standard.

Analysis was carried out using a holder to minimize contact between plastic and paper as described in previous work (Figure 2$)^{41}$. The holder supports a plastic pipette tip that holds solvent and an alligator clip that holds the sample square and paper tip. The paper tip was positioned in front of the inlet of a Thermo Fisher Scientific Q-Exactive Focus orbitrap mass spectrometer. $60 \mu \mathrm{L}$ of spray solvent, 80:20 acetonitrile:methanol with $25 \mathrm{mM}$ sulfuric acid $^{43}$, was added to the pipette tip. After the solvent flowed through the sample square to the paper spray tip clipped beneath it, $4.5 \mathrm{kV}$ of voltage was applied via a secondary alligator clip for 1 minute. The instrument was run in parallel reaction monitoring (PRM) mode, and the area under the curve (AUC) for the most abundant fragment for each compound was integrated. THC, 11-OH-THC, and $\mathrm{COOH}$ THC all used the same fragment of 193.1221 (within 5 ppm precision) as shown in figure 3 .

The ratios of the AUC for the analyte divided by its SIL were compared between samples dried for different lengths of time and with different oils. A similar experiment, described in the supplementary material, was conducted to test the preserving capability of a synthetic sesame oil consisting of the same natural oils as sesame oil mixed with the sesame oil antioxidants sesamin and sesamolin ${ }^{44}$ or the food preservative butylated hydroxytoluene.

\section{Preconcentration Using Paper Strip Extraction}

To analyze larger volumes of urine, samples were prepared using a technique termed paper strip extraction. Strips of 3MM chromatography paper were cut into $5 \mathrm{~mm} \times 40 \mathrm{~mm}$ strips, and $2.5 \mu \mathrm{L}$ of sesame seed oil was spotted at one end of each strip and allowed to wick through the paper. Extraction was carried out while the oil was still wet. Using a glass capillary, $50 \mu \mathrm{L}$ of urine was applied to the end of the strip containing the sesame oil and allowed to dry. After drying, the first $5 \mathrm{~mm}$ segment of the strip was removed for analysis as shown in figure 4. An experiment, described in the supplementary info (figure S-2), was conducted to determine whether analytes preconcentrated in the first $5 \mathrm{~mm}$ of the strip during this step. The analytes for this experiment included drugs with a range of $\log \mathrm{P}$ values to determine if hydrophobicity was a factor in analyte preconcentration.

To evaluate analyte preservation, a calibration curve was generated in urine spiked at $0.5,5$, 10, 100, 500 and $1000 \mathrm{ng} / \mathrm{mL}$ for THC, 11-OH-THC, THC-COOH, AB-CHMINACA, AM-2201, and fentanyl. THC-glucuronide was excluded due to its tendency to hydrolyze into THC-COOH. The internal standard consisted of a mixture of SIL analogs spiked into each calibrator at $100 \mathrm{ng} / \mathrm{mL}$. Two replicates were extracted and analyzed at each 
concentration as well as three blanks. Calibration curves with or without sesame oil were analyzed after 1, 7, and 27 days. Samples were stored in the dark at room temperature in a loosely covered plastic dish. The slope and Y-intercept were determined by linear regression ${ }^{45}$ with a weighting factor of $1 / \mathrm{X}^{2}$. Samples showing no signal or signal lower than three standard deviations above the average blank signal were omitted. Detection limits were calculated as three times the standard error of the Y-intercept divided by the slope.

\section{Preconcentration Effects on Detection Limits}

Samples were prepared in oral fluid and urine by either paper strip extraction or direct spotting on paper for a total of four combinations to determine whether this method had a noticeable impact on detection limits. Urine was spiked at 0.5, 5, 25, 100, 500 and 1000 $\mathrm{ng} / \mathrm{mL}$ of THC, 11-OH-THC, THC-COOH, AB-CHMINACA, AM-2201, 5F-ADB and ABCHMINACA metabolite 4 (structures shown in Figure 1) and $100 \mathrm{ng} / \mathrm{mL}$ SIL analogs for each analyte was spiked into each calibrator except 11-OH-THC and THC-COOH. Isotopically labeled THC was used as the internal standard for these two metabolites. Paper strip extraction was carried out as described earlier, and direct spotting was done by spotting $5 \mu \mathrm{L}$ of the urine or oral fluid directly onto $5 \mathrm{~mm}$ segments of paper. For samples prepared with oil but without paper strip extraction, a strip of paper with oil was prepared as normal, after the oil distributed on the paper the first $5 \mathrm{~mm}$ segment was removed and spiked with urine or oral fluid. Two replicates at each concentration and three blanks were analyzed after 1 and 28 days to evaluate the effects of preconcentration and preservation.

\section{Automated Analysis}

To show proof-of-concept for rapid screening, a prototype disposable cartridge was designed to be analyzed using a commercially available autosampler (the Velox from Prosolia). The cartridge consisted of two parts that snapped together around the sample square and paper spray tip. The bottom half and steel ball bearing, used as an electrical contact, from the original autosampler cartridge were used with a 3D printed top modeled in Sketchup and printed using polypropylene filament on an Ultimaker 2 extended+. 5-fluoro ADB metabolite 2 was analyzed in addition to the analytes mentioned earlier.

\section{Results and Discussion}

\section{Sesame Oil Preservation}

(-)-trans- $\Delta^{9}$-tetrahydrocannabinol (THC) and its metabolites can be difficult to analyze because they are unstable. THC, for example, will oxidize into cannabinol without preservation ${ }^{43}$. Additionally, due to their hydrophobicity, a significant portion of THC can be lost to plastic containers from aqueous matrices like urine ${ }^{42}$. Dronabinol, the synthetic version of THC sold for pharmaceutical purposes, uses sesame seed oil to preserve THC for extended periods of time at room temperature ${ }^{43}$. To determine whether this preservation could be extended to dried urine spots, sesame seed oil was added to the paper used to store the sample. Two additional oils were also tested as a comparison: oleic acid, a major component of sesame seed oil, and mineral oil, a petroleum-based oil without fatty acids. The amount of analyte remaining after storage was measured as a relative amount compared to the SIL spotted just before analysis. Preservation is reported here as the percent analyte 
remaining in samples that had been dried for an hour compared to samples that had been dried for a day (Figure 5).

Without oil, THC and its metabolites showed a significant drop over the course of a day while the two synthetic cannabinoids and fentanyl did not, indicating that the synthetic drugs were more stable than the natural cannabinoids in the dried urine spot. Of the three oils tested, only sesame seed oil effectively preserved THC. Sesame seed oil is a mixture of fatty acids, antioxidants, and other natural products ${ }^{44}$, 46 . A previous study on dronabinol indicated that the antioxidants within the oil likely helped THC preservation ${ }^{43}$. To test whether antioxidants were the reason THC was preserved in dried urine spots, a mixture of oleic, linoleic and palmitic acid in a similar ratio as sesame seed oil was tested. The synthetic sesame seed oil was also spiked either with the naturally occurring antioxidants sesamin and sesamolin or with the food preservative butylated hydroxytoluene (described in the supporting info). Synthetic sesame oil with antioxidants did not preserve THC as well as sesame seed oil (table S-1 in the supplementary information), indicating that the preservation of THC in urine spots using sesame seed oil is due to more than just the antioxidant content of the oil.

\section{Preconcentration Using Paper Strip Extraction}

The fact that THC adsorbs onto plastic container walls from urine prompted the idea that it could be extracted from urine as it flows through a hydrophobic matrix, such as sesame seed oil on a strip of paper. This process is referred to here as paper strip extraction (shown in Figure 4). Samples were flowed through a $40 \mathrm{~mm}$ long strip of paper containing sesame seed oil; the first $5 \mathrm{~mm}$ segment was then trimmed off and analyzed by paper spray MS. This method of extraction was evaluated with a variety of analytes with varying $\log P$ values to determine how they would distribute on the paper strip. It was found that hydrophobic analytes, analytes with a high $\log \mathrm{P}$ value like $\mathrm{THC}^{47}$ and synthetic cannabinoids, tended to preconcentrate at the beginning of the paper strip with or without oil. Detailed results for this experiment can be found in supplementary figure S-3 and the accompanying discussion. This meant that there were two potential mechanisms for improving detection limits using paper strip extraction; preservation from sesame seed oil and preconcentration of hydrophobic analytes.

To determine the effect of preservation on detection limits over time, calibration curves were prepared for THC in water by paper strip extraction with and without sesame seed oil. Extraction was carried out, and the $5 \mathrm{~mm}$ sample segments were stored at room temperature in a drawer for 1, 7 and 27 days prior to analysis. The preservation effects of sesame seed oil are best illustrated by looking at the calibration curves obtained for THC without sesame seed oil before and after 27 days of storage (Figure 6: A1 and A2 respectively) compared to with sesame seed oil over the same length of time (figure 6: B1 and B2 respectively). By day 27, the samples without the preserving oil only had detectable THC in the two highest concentration standards (Figure 6: A2). The samples stored with sesame seed oil, on the other hand, still showed signal down to $10 \mathrm{ng} / \mathrm{mL}$, demonstrating a marked improvement in stability for THC (Figure 6: B2). The high A/IS ratio in Figure 6: A2 was due to degradation of the internal standard to below the detection limit. This caused the $\mathrm{Y}$ intercept to be 
heavily skewed high relative to the other three calibration curves (the data points are still shown to give an estimate of the detection limit).

The lowest detectable concentrations at different time intervals for each analyte were determined based on the standard error of the Y-intercept and slope of the calibration curves. Calibration curve information is shown in table 1; detection limits can be found in table 2 . Fentanyl was included as a non-cannabinoid comparison. The synthetic cannabinoids showed minimal change over time, with or without the addition of oil. THC and 11-OHTHC show a measurable increase in the lowest detectable concentration over time without sesame seed oil. THC-COOH showed significant degradation over time even with sesame seed oil, albeit still improved over no preservative.

\section{Preconcentration Effects on Detection Limits}

In the previous section, it was shown that sesame seed oil preserves THC. To independently determine the contributions of preconcentration versus preservation on the detection limits, urine samples were analyzed with and without preconcentration. Oral fluid and urine were stored on paper with sesame seed oil both with and without performing paper strip extraction. Urine samples were analyzed after 1 day and 28 days of storage (table 3 ). Oral fluid was added as a second, non-invasive, biofluid (table 4). Both urine and oral fluid showed a noticeable improvement in detection limits of THC from preconcentration. THC$\mathrm{COOH}$ likewise showed a significant improvement in the detection limits with preconcentration, more than an order of magnitude for both urine and oral fluid. As in the earlier experiments detailed in table 2, THC-COOH did show some degradation after 28 days even with the oil. The metabolite AB-CHMINACA M4, which is more hydrophilic than AB-CHMINACA, showed elevated detection limits relative to AB-CHMINACA under all conditions. The calibration curves for 11-OH-THC and THC-COOH occasionally showed noticeably lower $\mathrm{r}^{2}$ values than THC (as shown in table 1) and higher limits of detection. This could be due to the lower hydrophobicity of the metabolites ${ }^{48}$ or because the metabolites did not use an isotopically labeled analog as the internal standard. AM-2201 and AB-CHMINACA gave similar results regardless of the biofluid, preconcentration, or storage time. 5F-ADB in most cases showed about an order of magnitude improvement in its detection limit when performing paper strip extraction. These results suggest that paper strip extraction has the potential to improve the detection limits for synthetic cannabinoids relative to directly spotting the analyte on paper, but it is not consistent and is analyte dependent. Importantly, the detection limits for the synthetic cannabinoids did not increase with the addition of oil, meaning that both natural and synthetic cannabinoids can be detected with the same method.

\section{Automated Analysis}

Any modifications to paper spray should maintain the speed and simplicity of the technique; otherwise those modifications risk defeating the purpose of paper spray. Ideally, the analysis would also be compatible with automation to enable high throughput analysis. A prototype paper spray cartridge was developed to demonstrate the potential for simple, fast, and automated implementation of paper strip extraction. The top half of the cartridge was 3D printed in polypropylene (top part of Figure 7:A, printing details in supplementary 
information) and the bottom half came from an injection molded paper spray autosampler cartridge (bottom part of Figure 7:A). Polypropylene was selected for the top half due to its resistance to organic solvents. When the top half was snapped onto the bottom half, it made a seal around the sample square to flow solvent through the sample to the paper spray substrate.

A calibration curve was generated using the prepared cartridges to determine the LODs (results in Table 5). THC and the three synthetic cannabinoids cannabinoid metabolites all gave roughly similar results to the manual experiments considering the variability in calculating detection limits such as day-to-day variation in the mass spectrometer and lot-tolot variability in the urine samples. AB-CHMINACA M4 gave a lower detection limit (20 $\mathrm{ng} / \mathrm{mL}$ versus 100 ), but analysis of this compound was more variable on the whole due to the lack of an isotopically labeled analog. THC-COOH was also run in this experiment, but there were insufficient data points for a calibration curve. It is possible that some interferent eluting from the 3D printed plastic specifically affected THC-COOH ionization. Beyond this anomaly, the autosampler cartridge results showed that the paper strip extraction technique is compatible with automation.

\section{Suitability for Cannabinoid Testing}

The usefulness of paper strip extraction lies in having a technique capable of simultaneous and rapid detection of both synthetic and natural cannabinoids. To be a valid option for applications such as determining driving under the influence of drugs (DUID) or workplace drug screening, the technique must be sensitive enough to at least detect levels indicative of recent use in that specific biofluid. Current workplace drug testing methods typically focus on THC-COOH as a biomarker in urine with cut offs at $50 \mathrm{ng} / \mathrm{mL}$ for the initial screen and $15 \mathrm{ng} / \mathrm{mL}$ for the subsequent confirmation ${ }^{10}$. Paper strip extraction detection of THC-COOH showed some problems. THC-COOH detection limits got noticeably higher over time relative to $\mathrm{THC}$, indicating that $\mathrm{THC}-\mathrm{COOH}$ was unstable in urine spots even with sesame seed oil (although the degradation was slower than without oil). Also, the detection limits for THC-COOH were significantly elevated in oral fluid and when using the automated cartridge. These results cast doubt on using paper strip extraction for routine detection of THC-COOH. However, THC-COOH is a metabolite that can be present for days in the body at variable levels over time depending on the frequency of use ${ }^{49}$, and thus is not a good marker on its own for determination of recent use in cases of DUID 5 .

For recent use, THC has been proposed as a better biomarker, as its presence in urine and oral fluid spikes within a few hours of use and drops off quickly ${ }^{50-52}$. For urine samples, the low $\mathrm{ng} / \mathrm{mL}$ detection limits obtained by paper strip extraction are close to the $1.5 \mathrm{ng} / \mathrm{mL}$ cutoff proposed as an indication of recent use ${ }^{51}$. For oral fluid, the concentration of THC can vary quite a bit after recent use ${ }^{50}$, but the cut-off concentration for THC from Substance Abuse and Mental Health Services Administration (SAMHSA) is $2 \mathrm{ng} / \mathrm{mL}^{53}$ and the cut-off for DUID from the European Union's Driving Under the Influences of Drugs, Alcohol, and Medicines (DRUID) is $1 \mathrm{ng} / \mathrm{mL}^{54}$. This also lies within the range detectable by paper strip extraction, although some further refinement of the technique and improvement in the detection limits are needed to decrease false negatives for samples near the cut-off value. 
Finally, addition of the internal standard needs consideration in future method development. In our long-term storage experiments, we spiked THC D3 prior to storage. Although our experiments indicated that THC D3 was preserved by sesame oil up to 28 days, longer-term storage could result in loss of internal standard signal.

A significant limitation is also the inability of paper spray MS/MS to distinguish the isomers THC and cannabidiol (CBD) without chromatographic separations ${ }^{39}$. This would likely result in false positives for individuals using CBD for legal, medicinal purposes. Follow-up confirmatory testing would therefore be essential. Despite these limitations, paper spray coupled to paper strip extraction shows good promise for rapidly screening both synthetic and natural cannabinoids from urine or oral fluid samples.

\section{Conclusion}

A method of concentrating and preserving THC and its metabolites in urine or oral fluid spots was demonstrated and integrated into a cartridge compatible with a paper spray autosampler. By flowing urine or oral fluid through paper, synthetic and natural cannabinoids were retained at the head of the paper. THC, which is normally labile and difficult to analyze from a urine or oral fluid spot, was preserved for at least 27 days at room temperature with the addition of sesame seed oil to the paper. Combining these two techniques improved detection limits for THC to $\mathrm{ng} / \mathrm{mL}$ levels in urine and oral fluid, close to current cut-off values for detection in cases of DUID. While differentiating isomers (such as THC and CBD) is still a problem for ambient ionization techniques, this method was also able to simultaneously detect natural and synthetic cannabinoids from a sample stored on paper.

\section{Supplementary Material}

Refer to Web version on PubMed Central for supplementary material.

\section{Acknowledgments}

Funding for this research was provided by a grant from the National Institute of Justice, Office of Justice Programs under award number 2016-DN-BX-007, by the National Institute on Drug Abuse of the National Institutes of Health under award number R21DA043037, and by Indiana University's Responding to the Addictions Crisis Grand Challenges initiative.

\section{References}

1. Sempio C; Scheidweiler KB; Barnes AJ; Huestis MA, Optimization of recombinant $\beta$-glucuronidase hydrolysis and quantification of eight urinary cannabinoids and metabolites by liquid chromatography tandem mass spectrometry. Drug Test. Anal 2018, 10 (3), 518-529. [PubMed: 28815938]

2. Robinson A Where states stand on legalizing recreational and medical marijuana; abc News: 7/14/2018, 2018.

3. Chavan S; Roy V, Designer drugs: a review. World J. Pharm. Pharm. Sci 2015, 4 (8), 297-336.

4. 2017 National Drug Threat Assessment; U.S. Department of Justice Drug Enforcement Administration: 2017.

5. Bondallaz P; Favrat B; Chtioui H; Fornari E; Maeder P; Giroud C, Cannabis and its effects on driving skills. Forensic Sci. Int 2016, 268, 92-102. [PubMed: 27701009] 
6. Declues K; Perez S; Figueroa A, A 2-Year Study of $\Delta$ 9-tetrahydrocannabinol Concentrations in Drivers: Examining Driving and Field Sobriety Test Performance. J. Forensic Sci 2016, 61 (6), 1664-1670. [PubMed: 27479468]

7. Hadener M; Kamrath MZ; Weinmann W; Groessl M, High-resolution ion mobility spectrometry for rapid cannabis potency testing. Anal. Chem. (Washington, DC, U. S.) 2018, 90 (15), 8764-8768.

8. Castellanos D; Gralnik LM, Synthetic cannabinoids 2015: An update for pediatricians in clinical practice. World Journal of Clinical Pediatrics 2016, 5 (1), 16-24. [PubMed: 26862498]

9. Tait RJ; Caldicott D; Mountain D; Hill SL; Lenton S, A systematic review of adverse events arising from the use of synthetic cannabinoids and their associated treatment. Clin. Toxicol 2015, Ahead of Print.

10. Kulig K, Interpretation of Workplace Tests for Cannabinoids. J. Med. Toxicol 2017, 13 (1), 106110. [PubMed: 27686239]

11. Smith FP, Handbook of Forensic Drug Analysis. Elsevier Academic Press: Burlington, MA, 2005; $\mathrm{p} 46$.

12. Wu AH; Gerona R; Armenian P; French D; Petrie M; Lynch KL, Role of liquid chromatographyhigh-resolution mass spectrometry (LC-HR/MS) in clinical toxicology. Clin. Toxicol 2012, 50 (8), 733-742.

13. Meier U; Dussy F; Scheurer E; Mercer-Chalmers-Bender K; Hangartner S, Cannabinoid concentrations in blood and urine after smoking cannabidiol joints. Forensic Sci. Int 2018, 291, 62-67. [PubMed: 30149280]

14. Rodrigues A; Yegles M; Van Elsue N; Schneider S, Determination of cannabinoids in hair of CBD rich extracts consumers using gas chromatography with tandem mass spectrometry (GC/MS-MS). Forensic Sci. Int 2018, Ahead of Print.

15. Hoofnagle AN; Wener MH, The fundamental flaws of immunoassays and potential solutions using tandem mass spectrometry. J. Immunol. Methods 2009, 347 (1-2), 3-11. [PubMed: 19538965]

16. Takats Z; Wiseman JM; Gologan B; Cooks RG, Mass Spectrometry Sampling Under Ambient Conditions with Desorption Electrospray Ionization. Science (Washington, DC, U. S.) 2004, 306 (5695), 471-473.

17. Robert B Cody JAL, Michael Nilles J and Dupont Durst H, Direct Analysis in Real Time (DART) Mass Spectrometry. JEOL News 2005, 40 (1), 8-12.

18. Steiner RR; Larson RL, Validation of the direct analysis in real time source for use in forensic drug screening. J. Forensic Sci 2009, 54 (3), 617-622. [PubMed: 19302399]

19. Gurdak E; Green FM; Rakowska PD; Seah MP; Salter TL; Gilmore IS, VAMAS Interlaboratory Study for Desorption Electrospray Ionization Mass Spectrometry (DESI MS) Intensity Repeatability and Constancy. Anal. Chem. (Washington, DC, U. S.) 2014, 86 (19), 9603-9611.

20. Lawton ZE; Traub A; Fatigante WL; Mancias J; O'Leary AE; Hall SE; Wieland JR; Oberacher H; Gizzi MC; Mulligan CC, Analytical Validation of a Portable Mass Spectrometer Featuring Interchangeable, Ambient Ionization Sources for High Throughput Forensic Evidence Screening. J. Am. Soc. Mass Spectrom 2017, 28 (6), 1048-1059. [PubMed: 28000107]

21. Elmiger MP; Poetzsch M; Steuer AE; Kraemer T, Parameter Optimization for Feature and Hit Generation in a General Unknown Screening Method-Proof of Concept Study Using a Design of Experiment Approach for a High Resolution Mass Spectrometry Procedure after Data Independent Acquisition. Anal. Chem. (Washington, DC, U. S.) 2018, 90 (5), 3531-3536.

22. Pavlovich MJ; Musselman B; Hall AB, Direct analysis in real time-mass spectrometry (DART-MS) in forensic and security applications. Mass Spectrom. Rev 2018, 37 (2), 171-187. [PubMed: 27271453]

23. Liu J; Wang H; Manicke NE; Lin J-M; Cooks RG; Ouyang Z, Development, Characterization, and Application of Paper Spray Ionization. Anal. Chem. (Washington, DC, U. S.) 2010, 82 (6), $2463-$ 2471.

24. Wang H; Liu J; Cooks RG; Ouyang Z, Paper Spray for Direct Analysis of Complex Mixtures Using Mass Spectrometry. Angew. Chem., Int. Ed 2010, 49 (5), 877-880, S877/1-S877/7.

25. Manicke NE; Bills BJ; Zhang C, Analysis of biofluids by paper spray MS: advances and challenges. Bioanalysis 2016, 8 (6), 589-606. [PubMed: 26916068] 
26. Damon DE; Davis KM; Moreira CR; Capone P; Cruttenden R; Badu-Tawiah AK, Direct Biofluid Analysis Using Hydrophobic Paper Spray Mass Spectrometry. Anal. Chem. (Washington, DC, U. S.) 2016,88 (3), 1878-1884.

27. Shi R-Z; El Gierari ETM; Faix JD; Manicke NE, Rapid measurement of cyclosporine and sirolimus in whole blood by paper spray-tandem mass spectrometry. Clin. Chem. (Washington, DC, U. S.) 2016, 62 (1), 295-299.

28. Bills BJ; Manicke NE, Development of a prototype blood fractionation cartridge for plasma analysis by paper spray mass spectrometry. Clinical Mass Spectrometry 2016, 2 (Supplement C), $18-24$.

29. Maher S; Jjunju FPM; Damon DE; Gorton H; Maher YS; Syed SU; Heeren RMA; Young IS; Taylor S; Badu-Tawiah AK, Direct Analysis and Quantification of Metaldehyde in Water using Reactive Paper Spray Mass Spectrometry. Sci. Rep 2016, 6, 35643. [PubMed: 27767044]

30. Ma Q; Bai H; Li W; Wang C; Cooks RG; Ouyang Z, Rapid analysis of synthetic cannabinoids using a miniature mass spectrometer with ambient ionization capability. Talanta 2015, 142, 190 196. [PubMed: 26003711]

31. Zhang C; Manicke NE, Development of a Paper Spray Mass Spectrometry Cartridge with Integrated Solid Phase Extraction for Bioanalysis. Anal. Chem. (Washington, DC, U. S.) 2015, 87 (12), 6212-6219.

32. Shi R-Z; El Gierari ETM; Manicke NE; Faix JD, Rapid measurement of tacrolimus in whole blood by paper spray-tandem mass spectrometry (PS-MS/MS). Clin. Chim. Acta 2015, 441, 99-104. [PubMed: 25540885]

33. Wang H; Ren Y; McLuckey MN; Manicke NE; Park J; Zheng L; Shi R; Cooks RG; Ouyang Z, Direct Quantitative Analysis of Nicotine Alkaloids from Biofluid Samples using Paper Spray Mass Spectrometry. Anal. Chem. (Washington, DC, U. S.) 2013, 85 (23), 11540-11544.

34. Su Y; Wang H; Liu J; Wei P; Cooks RG; Ouyang Z, Quantitative paper spray mass spectrometry analysis of drugs of abuse. Analyst (Cambridge, U. K.) 2013, 138 (16), 4443-4447.

35. Li A; Wei P; Hsu H-C; Cooks RG, Direct analysis of 4-methylimidazole in foods using paper spray mass spectrometry. Analyst 2013, 138 (16), 4624-4630. [PubMed: 23762894]

36. Espy RD; Manicke NE; Ouyang Z; Cooks RG, Rapid analysis of whole blood by paper spray mass spectrometry for point-of-care therapeutic drug monitoring. Analyst (Cambridge, U. K.) 2012, 137 (10), 2344-2349.

37. Manicke NE; Abu-Rabie P; Spooner N; Ouyang Z; Cooks RG, Quantitative analysis of therapeutic drugs in dried blood spot samples by paper spray mass spectrometry: an avenue to therapeutic drug monitoring. J. Am. Soc. Mass Spectrom 2011, 22 (9), 1501-1507. [PubMed: 21953253]

38. Yannell KE; Kesely KR; Chien HD; Kissinger CB; Cooks RG, Comparison of paper spray mass spectrometry analysis of dried blood spots from devices used for in-field collection of clinical samples. Anal. Bioanal. Chem 2017, 409 (1), 121-131. [PubMed: 27822645]

39. Espy RD; Teunissen SF; Manicke NE; Ren Y; Ouyang Z; van Asten A; Cooks RG, Paper Spray and Extraction Spray Mass Spectrometry for the Direct and Simultaneous Quantification of Eight Drugs of Abuse in Whole Blood. Analytical Chemistry 2014, 86 (15), 7712-7718. [PubMed: 24970379]

40. Atakan Z, Cannabis, a complex plant: different compounds and different effects on individuals. Ther Adv Psychopharmacol 2012, 2 (6), 241-254. [PubMed: 23983983]

41. Bills BJ; Kinkade J; Ren G; Manicke NE, The impacts of paper properties on matrix effects during paper spray mass spectrometry analysis of prescription drugs, fentanyl and synthetic canabinoids. Forensic Chemistry 2018, 11, 15-22.

42. White RM, Instability and poor recovery of cannabinoids in urine, oral fluid, and hair. Forensic Sci Rev 2018, 30 (1), 33-49. [PubMed: 29273570]

43. Wempe MF; Oldland A; Stolpman N; Kiser TH, Stability of dronabinol capsules when stored frozen, refrigerated, or at room temperature. Am. J. Health-Syst. Pharm 2016, 73 (14), 1088-1092. [PubMed: 27385703]

44. Tashiro T; Fukuda Y; Osawa T; Namiki M, Oil and minor components of sesame (Sesamum indicum L.) strains. Journal of the American Oil Chemists' Society 1990, 67 (8), 508-511. 
45. Almeida AM; Castel-Branco MM; Falcao AC, Linear regression for calibration lines revisited: weighting schemes for bioanalytical methods. J. Chromatogr. B: Anal. Technol. Biomed. Life Sci 2002, 774 (2), 215-222.

46. Jamieson GS; Baughman WF, THE CHEMICAL COMPOSITION OF SESAME OIL. Journal of the American Chemical Society 1924, 46 (3), 775-778.

47. Walpitagama M; Carve M; Douek AM; Trestrail C; Bai Y; Kaslin J; Wlodkowic D, Additives migrating from 3D-printed plastic induce developmental toxicity and neuro-behavioural alterations in early life zebrafish (Danio rerio). Aquat. Toxicol 2019, 213, 105227. [PubMed: 31226596]

48. Metabolite 11-Nor-9-carboxy-THC (THC-COOH). https://www.drugbank.ca/metabolites/ DBMET02064 (accessed 9/6/2019).

49. Musshoff F; Madea B, Review of Biologic Matrices (Urine, Blood, Hair) as Indicators of Recent or Ongoing Cannabis Use. Ther. Drug Monit 2006, 28 (2), 155-163. [PubMed: 16628124]

50. Marsot A; Audebert C; Attolini L; Lacarelle B; Micallef J; Blin O, Comparison of cannabinoid concentrations in plasma, oral fluid and urine in occasional cannabis smokers after smoking cannabis cigarette. J. Pharm. Pharm. Sci 2016, 19 (3), 411-422. [PubMed: 27806250]

51. Manno JE; Manno BR; Kemp PM; Alford DD; Abukhalaf IK; McWilliams ME; Hagaman FN; Fitzgerald MJ, Temporal indication of marijuana use can be estimated from plasma and urine concentrations of $\Delta 9$-tetrahydrocannabinol, 11-hydroxy- $\Delta 9$-tetrahydrocannabinol, and 11-nor- $\Delta 9$ tetrahydrocannabinol-9-carboxylic acid. J. Anal. Toxicol 2001, 25 (7), 538-549. [PubMed: 11599597]

52. Kidwell DA; Holland JC; Athanaselis S, Testing for drugs of abuse in saliva and sweat. J. Chromatogr. B: Biomed. Sci. Appl 1998, 713 (1), 111-135. [PubMed: 9700555]

53. SAMHSA, Mandatory guidelines for federal workplace drug testing programs Fed Reg 80:2805428101. 2015.

54. Swortwood MJ; Newmeyer MN; Abulseoud OA; Andersson M; Barnes AJ; Scheidweiler KB; Huestis MA, On-site oral fluid $\Delta$ 9-tetrahydrocannabinol (THC) screening after controlled smoked, vaporized, and oral cannabis administration. Forensic Toxicol. 2017, 35 (1), 133-145. 

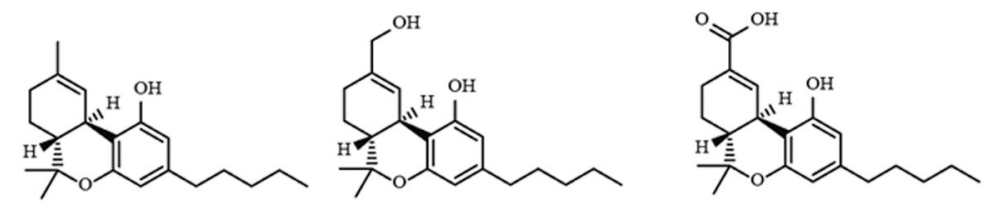

$(-)$-trans- $\Delta^{3}$-tetrahydrocannabinol 11-Hydroxy- $\Delta 9$-tetrahydrocannabinol 11-Nor-9-carboxy- $\Delta 9$-tetrahydrocannabinol
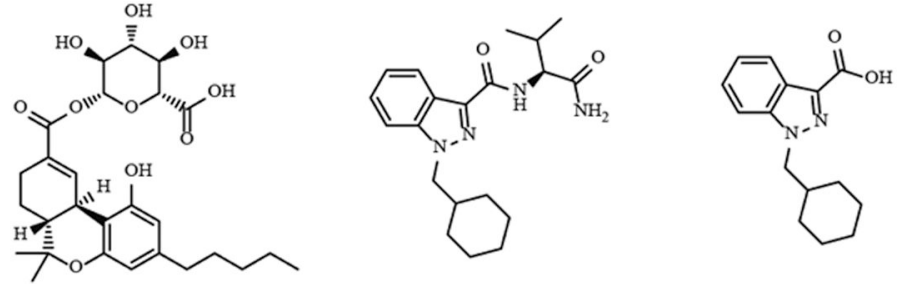

11-Nor-9-carboxy- $\triangle 9$-THC glucuronide

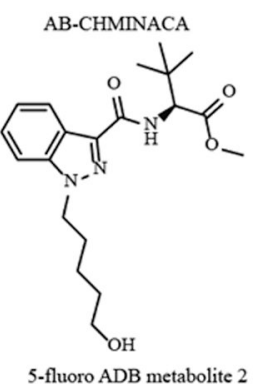

AB-CHMINACA metabolite 4

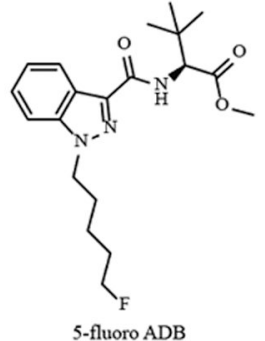

5-fluoro ADB metabolite 2

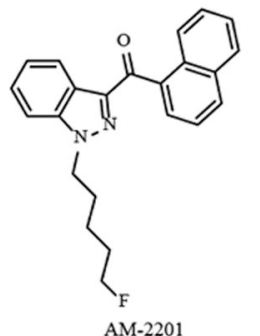

Figure 1:

Cannabinoid structures. 


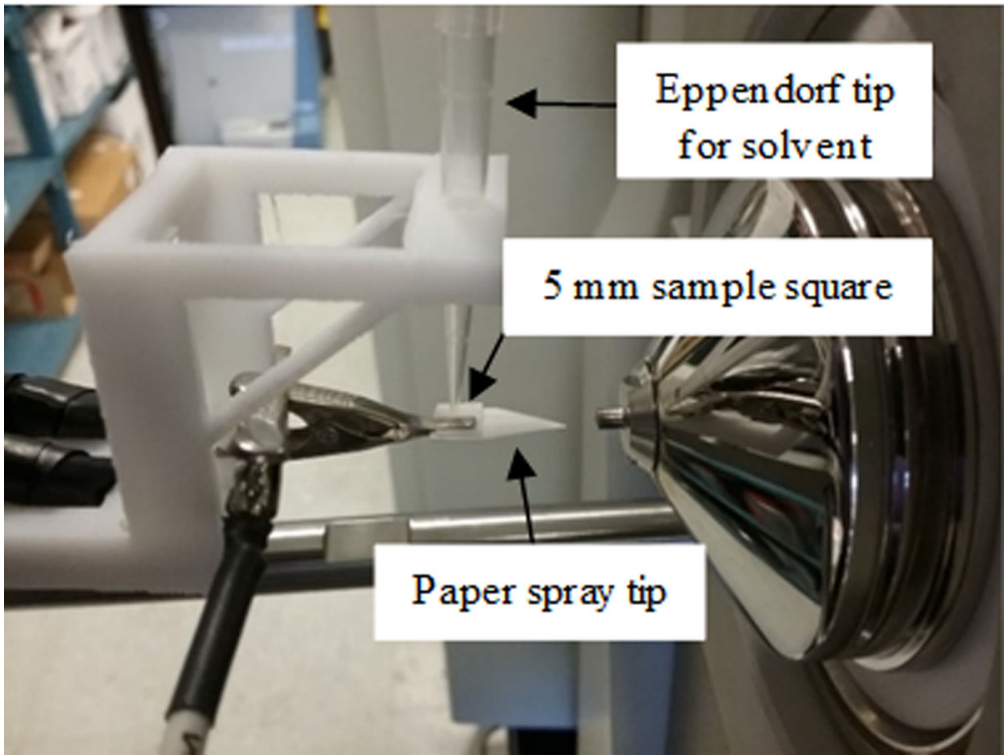

Figure 2:

Paper spray setup. A 3D printed support holding an alligator clip and Eppendorf tip to act as sample holder and solvent well respectively. 


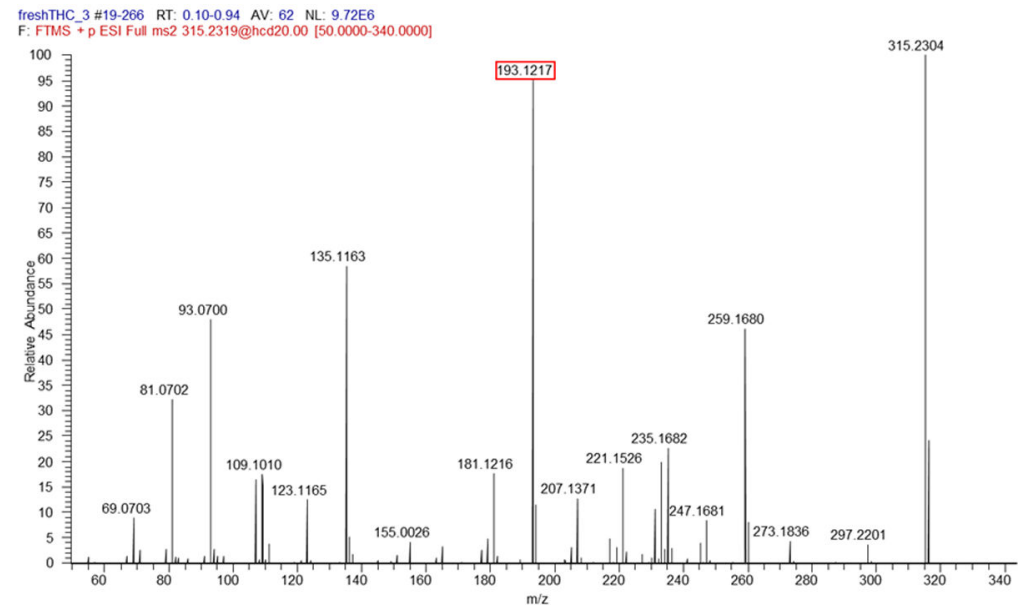

Figure 3:

MS/MS spectrum of THC with the most intense fragment highlighted. 


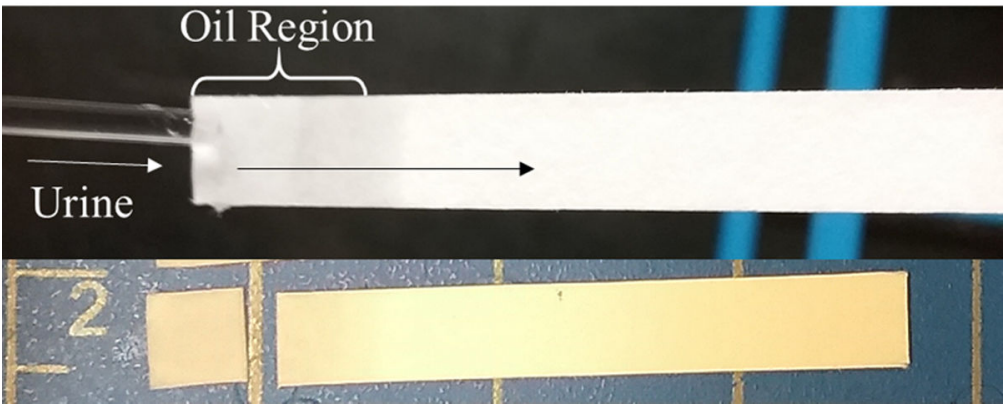

Figure 4:

Paper strip extraction. Top: Urine was flowed throw an oil spot on a strip of paper. Bottom: After drying the first $5 \mathrm{~mm}$ of strip was cut off and analyzed. 


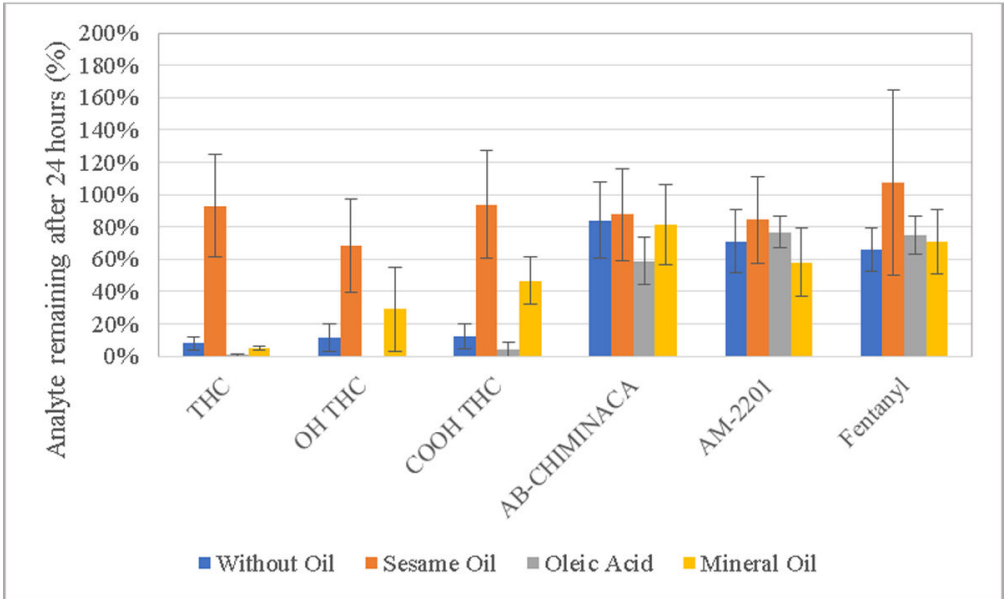

Figure 5:

Percent of analyte remaining (relative to freshly spotted internal standard) for dried urine samples after 24 hours storage versus one hour using different oils for preservation. 

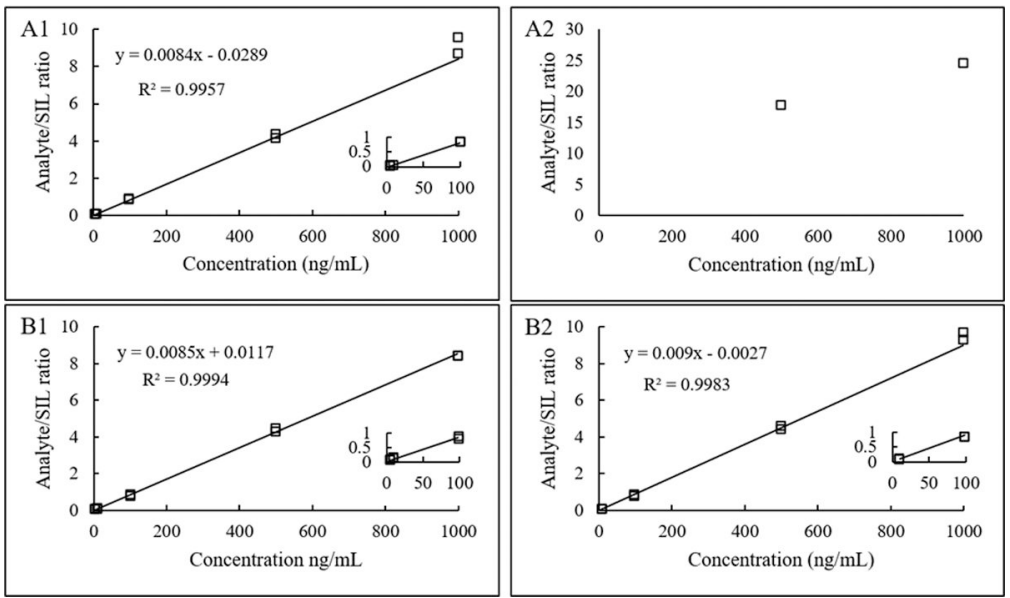

Figure 6:

Calibration curves for THC after 1 day (A1 and B1) and after 27 days (A2 and B2) using paper strip extraction without sesame seed oil (A1 and A2) and paper strip extraction with sesame seed oil (B1 and B2). 


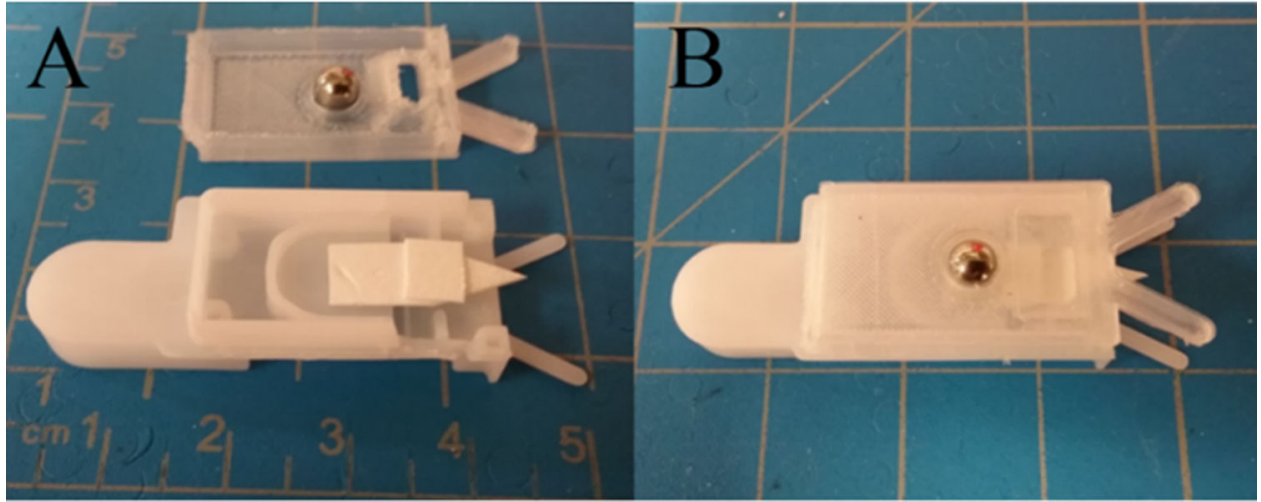

Figure 7:

Prototype paper strip extraction cartridge. A. 3D printed polypropylene top half and injection molded plastic bottom half, B. assembled cartridge. 
Table 1.

Slope, Y-intercept, and $\mathrm{R}^{2}$ values for the calibration curves after paper strip extraction with and without sesame seed oil after storage at room temperature.

\begin{tabular}{|c|c|c|c|c|c|c|}
\hline \multirow[b]{2}{*}{ Day 1} & \multicolumn{3}{|c|}{ No Oil } & \multicolumn{3}{|c|}{ Oil } \\
\hline & Slope & Y-intercept & $\mathbf{R}^{2}$ & Slope & Y-intercept & $\mathbf{R}^{2}$ \\
\hline THC & $0.0084 \pm 0.0005$ & $-0.029 \pm 0.005$ & 0.996 & $0.0085 \pm 0.0004$ & $0.012 \pm 0.004$ & 0.999 \\
\hline OH THC & $0.0014 \pm 0.0007$ & $0.003 \pm 0.007$ & 0.916 & $0.00095 \pm 0.00009$ & $0.003 \pm 0.001$ & 0.942 \\
\hline $\mathrm{COOH}$ THC & $0.0106 \pm 0.0003$ & $0.11 \pm 0.04$ & 0.998 & $0.0093 \pm 0.0005$ & $0.21 \pm 0.01$ & 0.997 \\
\hline AM-2201 & $0.047 \pm 0.001$ & $-0.07 \pm 0.01$ & 0.998 & $0.045 \pm 0.002$ & $-0.06 \pm 0.02$ & 0.999 \\
\hline AB-CHMINACA & $0.00430 \pm 0.00009$ & $-0.025 \pm 0.002$ & 0.997 & $0.0045 \pm 0.0002$ & $-0.011 \pm 0.004$ & 0.99 \\
\hline Fentanyl & $0.0081 \pm 0.0002$ & $-0.046 \pm 0.004$ & 0.996 & $0.0078 \pm 0.0004$ & $-0.073 \pm 0.009$ & 0.996 \\
\hline Day 7 & Slope & Y-intercept & $\mathrm{R}^{2}$ & Slope & Y-intercept & $\mathrm{R}^{2}$ \\
\hline THC & $0.011 \pm 0.009$ & $-0.5 \pm 0.1$ & 0.992 & $0.0087 \pm 0.0003$ & $-0.003 \pm 0.003$ & 0.997 \\
\hline OH THC & $0.0003 \pm 0.0002$ & $0.077 \pm 0.003$ & 0.937 & $0.0011 \pm 0.0001$ & $0.0005 \pm 0.0012$ & 0.863 \\
\hline $\mathrm{COOH}$ THC & $0.20 \pm 0.06$ & $-15 \pm 9$ & 0.861 & $0.0114 \pm 0.0007$ & $0.1 \pm 0.1$ & 0.958 \\
\hline AM-2201 & $0.045 \pm 0.002$ & $-0.06 \pm 0.02$ & 0.999 & $0.031 \pm 0.004$ & $0.051 \pm 0.006$ & 0.988 \\
\hline AB-CHMINACA & $0.0043 \pm 0.0002$ & $-0.003 \pm 0.002$ & 0.997 & $0.0043 \pm 0.0002$ & $-0.005 \pm 0.002$ & 0.999 \\
\hline Fentanyl & $0.0079 \pm 0.0001$ & $-0.003 \pm 0.002$ & 0.999 & $0.0078 \pm 0.0003$ & $-0.038 \pm 0.007$ & 0.999 \\
\hline Day 27 & Slope & Y-intercept & $\mathrm{R}^{2}$ & Slope & Y-intercept & $\mathrm{R}^{2}$ \\
\hline THC & $\mathrm{n} / \mathrm{a}$ & $\mathrm{n} / \mathrm{a}$ & $\mathrm{n} / \mathrm{a}$ & $0.0090 \pm 0.0004$ & $-0.003 \pm 0.008$ & 0.998 \\
\hline $\mathrm{OH}$ THC & $\mathrm{n} / \mathrm{a}$ & $\mathrm{n} / \mathrm{a}$ & $\mathrm{n} / \mathrm{a}$ & $0.00093 \pm 0.00005$ & $0.005 \pm 0.001$ & 0.992 \\
\hline $\mathrm{COOH}$ THC & $\mathrm{n} / \mathrm{a}$ & $\mathrm{n} / \mathrm{a}$ & $\mathrm{n} / \mathrm{a}$ & $0.024 \pm 0.005$ & $-1.2 \pm 0.9$ & 0.839 \\
\hline AM-2201 & $0.033 \pm 0.005$ & $0.02 \pm 0.05$ & 0.914 & $0.044 \pm 0.001$ & $-0.06 \pm 0.01$ & 0.999 \\
\hline AB-CHMINACA & $0.0044 \pm 0.0002$ & $0.008 \pm 0.004$ & 0.994 & $0.0042 \pm 0.0001$ & $0.012 \pm 0.002$ & 0.997 \\
\hline Fentanyl & $0.0077 \pm 0.0002$ & $-0.023 \pm 0.006$ & 0.999 & $0.0068 \pm 0.0008$ & $-0.05 \pm 0.02$ & 0.994 \\
\hline
\end{tabular}

* $\mathrm{n} / \mathrm{a}$ indicates there were insufficient data points to construct a calibration curve for that data set. 
Table 2.

Lowest detectable urine concentration $(\mathrm{ng} / \mathrm{mL})$ after paper strip extraction with and without sesame seed oil after storage at room temperature. Detection limits are three times the standard error of the Y-intercept divided by the slope.

\begin{tabular}{|lcccccc|}
\hline & \multicolumn{2}{c}{ Day 1 } & \multicolumn{2}{c|}{ Day 7 } & \multicolumn{2}{c|}{ Day 27 } \\
Analyte & No Oil & Oil & No Oil & Oil & No Oil & Oil \\
THC & 2 & 1 & 30 & 1 & $2500^{*}$ & 3 \\
11-OH-THC & 20 & 4 & 30 & 4 & $\geq 1000^{*}$ & 4 \\
THC-COOH & 10 & 5 & 130 & 30 & $\geq 1000^{*}$ & 120 \\
AM-2201 & 0.8 & 1 & 1 & 0.6 & 4 & 0.8 \\
AB-CHMINACA & 1 & 3 & 1 & 1 & 3 & 2 \\
Fentanyl & 2 & 3 & 0.8 & 3 & 2 & 7 \\
\hline
\end{tabular}

Detection limits significantly above the $100 \mathrm{ng} / \mathrm{mL}$ internal standard are rough estimates. 
Table 3.

Lowest detectable urine concentration $(\mathrm{ng} / \mathrm{mL})$ with and without paper strip extraction after storage at room temperature with sesame seed oil.

\begin{tabular}{|lcccc|}
\hline \multicolumn{1}{|c}{ Urine } & \multicolumn{2}{c}{ Day 1 } & \multicolumn{2}{c|}{ Day 28 } \\
THC & Without Preconcentration & With Preconcentration & Without Preconcentration & With Preconcentration \\
11-OH-THC & 20 & 2 & 10 & 2 \\
THC-COOH & 9 & 4 & 70 & 20 \\
AM-2201 & 200 & 10 & 2500 & 40 \\
AB-CHMINACA & 0.2 & 0.2 & 0.2 & 0.2 \\
AB-CHMINACA M4 & 1 & 0.2 & 1 & 2 \\
5F-ADB & 130 & 60 & 70 & 80 \\
\hline
\end{tabular}

Detection limits well above the $100 \mathrm{ng} / \mathrm{mL}$ internal standard are rough estimates. 
Table 4.

Lowest detectable oral fluid concentration $(\mathrm{ng} / \mathrm{mL})$ with and without paper strip extraction after storage at room temperature with sesame seed oil.

\begin{tabular}{|lcccc|}
\hline \multicolumn{1}{|c}{ Oral Fluid } & \multicolumn{2}{c}{ Day 1 } & \multicolumn{2}{c|}{ Day 28 } \\
THC & Without Preconcentration & With Preconcentration & Without Preconcentration & With Preconcentration \\
11 -OH-THC & 20 & 1 & 30 & 1 \\
THC-COOH & 4 & 3 & 70 & 5 \\
AM-2201 & 10 & 3 & $21000^{*}$ & 60 \\
AB-CHMINACA & 0.06 & 0.08 & 0.2 & 0.08 \\
AB-CHMINACA M4 & 4 & 0.6 & 3 & 2 \\
5F-ADB & 50 & 100 & 100 & 100 \\
\hline
\end{tabular}

Detection limits well above the $100 \mathrm{ng} / \mathrm{mL}$ internal standard are rough estimates. 
Table 5.

Detection limits in $\mathrm{ng} / \mathrm{mL}$ in oral fluid using sesame seed oil and paper strip extraction in a half 3D printed autosampler cartridge.

\begin{tabular}{|l|c|}
\hline Analyte & LOD \\
THC & 4 \\
5F-ADB & 0.1 \\
5F-ADB M2 & 0.5 \\
AB-CHMINACA & 6 \\
AM-2201 & 0.1 \\
AB-CHMINACA M4 & 20 \\
\hline
\end{tabular}

